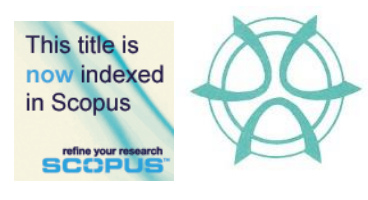

PLANNING MALAYSIA:

Journal of the Malaysian Institute of Planners

VOLUME 17 ISSUE 2 (2019), Page 191-202

\title{
INCOME PERSPECTIVE ON THE FACTORS INFLUENCING HOUSEHOLDS' RECYCLING INTENTION: IMPLICATIONS FROM THE EXTENDED THEORY OF PLANNED BEHAVIOUR
}

\author{
Muhammad Salisu Khalil ${ }^{1}$, Ho Yuek Ming ${ }^{2}$, Latifah Abd Manaf ${ }^{3}$, \\ Amir Hamzah Sharaai ${ }^{4}$, \& Aliyu Baba Nabegu ${ }^{5}$ \\ ${ }^{1,2,3,4,5}$ Faculty of Environmental Studies \\ UNIVERSITI PUTRA MALAYSIA
}

\begin{abstract}
Although few studies have attempted to explain residents' waste handling behaviour from social and psychological perspective, yet, there is little understanding regarding the influence of households' moral obligation, consequences awareness, and perceived lack of facilitating conditions on forming recycling intention. This study aims at investigating the key determinants of household recycling intention using the extended theory of planned behaviour (TPB). Data collected from 422 households in Kano metropolis were analysed using structural equation modelling to determine the influence of each predictor on the recycling intention. The results indicate that attitude, subjective norms, personal norm, consequences awareness and perceived lack of facilitating conditions significantly predict recycling intention, with attitude being the most significant predictor of households' intention. Additional analysis on the effect of households' income level on their recycling intention shows that income level moderates the relationships between attitude and recycling intention, personal norms-recycling intention, and perceived lack of facilitating conditionsrecycling intention. The findings provide valuable suggestions for recycling policies that can focus on households' intention formation by providing recycling facilities, encouraging participation through market-driven recycling programs, and promoting recycling awareness and education.
\end{abstract}

Keywords: Solid waste, recycling, households, behavioural intention, Kano metropolis 
Muhammad Salisu Khalil, Ho Yuek Ming, Latifah Abd Manaf, Amir Hamzah Sharaai, \& Aliyu Baba Nabegu Income Perspective on the Factors Influencing Households' Recycling Intention: Implications from the Extended Theory of Planned Behaviour

\section{INTRODUCTION}

Household solid waste (HSW) is the main source of municipal solid waste (MSW) in many countries to which most cost of the waste management is allocated (Parkpour, Zeidi, Emamjomeh, Asefzadeh, \& Pearson, 2014). In spite of the huge allocation, improper handling and disposal of the wastes has been a major challenge and a growing concern in many countries, particularly in developing nations.

Landfilling has been a major way of solid waste disposal in many countries across the world. The rate of landfilling is higher than the sustainable waste reduction and recycling in many African and east European nations (PérezLópez et al., 2016). However, landfilling is detrimental to the environment and public health, and results to high rates of morbidity and mortality (Pérez-López, Prior, Zafra-Gómez, \& Plata-Díaz, 2016). Waste recycling seemed to be a fundamental scheme that can be used to achieve a sustainable management of municipal solid waste as it has significant environmental and economic benefits (Khalil, Abdullah, Abd Manaf, Sharaai, \& Nabegu, 2017). In spite of its importance, low participation of residents in recycling has been reported in most developing countries. For example, previous studies reported that more than half of all the solid waste generated is recyclable, however, only about $2 \%$ of the wastes produced are recycled due to lack of residents' participation in recycling (Khalil et al., 2017).

Past literature on household solid waste recycling has focused mainly on four aspects of recycling, namely; determinants of waste recycling behaviour, efficiency of waste recycling schemes, and the partnerships between formal and informal recycling sectors (Wan, Shen, \& Yu, 2014; Xu, Ling, Lu, \& Shen 2017). However, only few studies discussed about the effectiveness of waste separation and recycling policies (Wan et al., 2014; Xu et al., 2017). This study seeks to investigate the moderating effect of a demographic variable on factors influencing residents' recycling intention in Kano metropolis Nigeria by extending the theory of planned behaviour.

\section{THEORETICAL FRAMEWORK}

\section{Theory of Planned Behaviour (TPB)}

Theory of Planned Behaviour (TPB) proposed that people's intention to perform a behaviour depends on their "behavioural beliefs" about the outcome of the behaviour, "normative beliefs" about the expectations of important people around them, as well as their "control belief" about performing the behaviour and the likely obstacles (Ajzen, 1991). These three beliefs give rise to the formation of attitudes, subjective norms, and perceived behavioural control respectively, which subsequently influence people's intention to perform an action (Ajzen, 
1991). Additionally, when the perceived behavioural control is high, it can directly influence behaviour (Chen \& Tung, 2010).

The present study extends the TPB framework to increase its predictive capacity. Personal norms, consequences awareness, perceived lack of facilitating conditions (residents' perception about availability of recycling facilities and its effect on their recycling intention) and a demographic variable (income level) were included in the TPB framework (Figure 1).

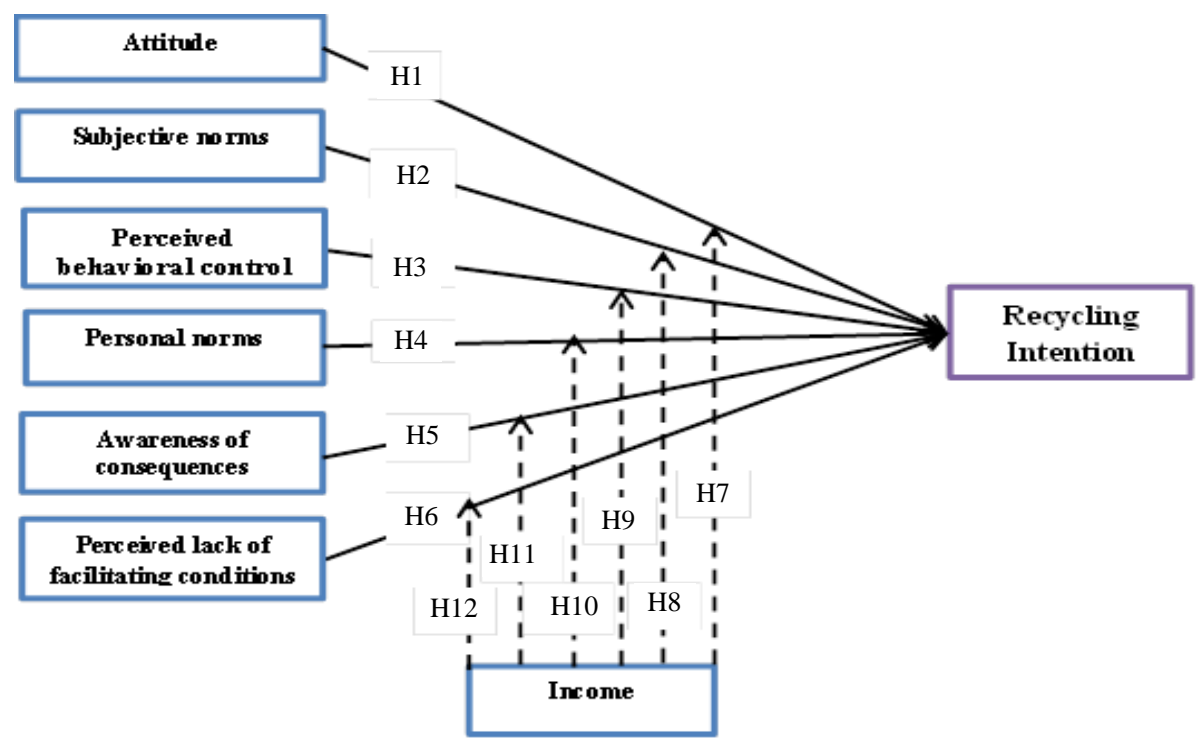

Figure 1 The extended theory of planned behaviour (TPB)

\section{MATERIALS AND METHODS}

\section{Sampling Design and Participants of the Study}

In this study, the respondents constitute households residing within Kano metropolis. With an estimated population of 477,805 households, Kano metropolis is composed of two income groups: the high income households residing mainly in the GRA, and the low income households that dominated the suburban areas (Suleyman \& Khalil, 2014). The sample size for this study was determined as 384 using Krejcie and Morgan (1970) estimation. However, to avoid the problems of unreturned and unattended questionnaires, $10 \%$ oversampling was added to arrive at 422 households as suggested by Singh and Masuku (2014). A multistage sampling technique was adopted to select the participants for this study. Participants were selected proportionately from the two income groups based on their total population number. The distribution of the respondents in the study area from where the sample was drawn is as follows: 
Muhammad Salisu Khalil, Ho Yuek Ming, Latifah Abd Manaf, Amir Hamzah Sharaai, \& Aliyu Baba Nabegu Income Perspective on the Factors Influencing Households' Recycling Intention: Implications from the Extended Theory of Planned Behaviour

low income areas have 251,660 households, and its proportionate sample was 236.94 (52.64\%), Nassarawa (high income) has 226,145 households, and its proportionate sample was $213.058(47.33 \%)$.

Questionnaires were administered with the help of research assistants between September and November, 2017. From the 422 returned questionnaires, about 29 were found to have a significant missing data; hence they were removed using a list wise deletion method. This method reduced the sample to 393, making the response rate of the completed questionnaire to be $93.77 \%$, which is considered adequate enough for the analysis of this study.

\section{Measures}

This study adopted and modified the instrument from previous study by Chen and Tung (2010), a five-point Likert scale was used to assess the respondents' level of agreement to each statement measuring the constructs from $1=$ strongly disagree to 5=strongly agree. In the first section of the instrument, participants were asked to respond to demographic questions and in the second section participants were asked to respond to questions on latent constructs.

\section{Data analysis}

The analyses performed in this study include the descriptive statistics in which the participants' demographic characteristics were analysed. Subsequently, confirmatory factor analysis (CFA) was conducted to test the validity and reliability of the variables in the model. Additionally, structural equation modelling analysis was carried out to determine the individual and collective contribution of the predictor variables on the recycling intention. Finally, the study utilises Multi-Group Analysis technique in order to test the moderating effect of income on the relationships between the predictor variable and recycling intention. All these analyses were made possible using SPSS version 20 and AMOS version 22 statistical tools.

\section{RESULTS AND DISCUSSION}

\section{Result of the Descriptive Analysis}

Of the 393 respondents, majority of them $(50.9 \%)$ were male and the rest were female. Most of the households were within the age bracket 35-49 years old while only few $(1.3 \%)$ were above 65 years of age. Additionally, majority of the respondents $(62.8 \%)$ attained a tertiary education level, and $52.64 \%$ of them reside in low income area. $43.3 \%$ of the households have their monthly income between N150001-N300000 (\$416-\$833). The household size of majority of the respondents $(36.1 \%)$ ranges between 5-8 people. 


\section{The Measurement Model}

Confirmatory factor analysis was conducted to test for the fitness of the data; composite reliability, discriminant and convergent validity of the model. Indices were used to assess the fitness of the model as suggested by Hayes and Scharkow, (2013), these are: (CMIN/df $\leq 5)$, (NFI $\geq 0.90)$, (CFI $\geq 0.90)$, (AGFI $\geq 0.90)$, (GFI $\geq 0.90$ ), (RAMSEA $\leq 0.08)$. A measurement model is considered fit if it achieved at least three or four of the recommended goodness-of-fit indices. Based on the criteria suggested by Hair, Black, Babin and Anderson (2010), the model met the recommended goodness-of-fit indices value as shown in Table 1:

Table 1 Summary of the goodness-of-fit indices of the measurement model of this study

\begin{tabular}{ccccccccc}
\hline CMIN & $\boldsymbol{d F}$ & $\begin{array}{c}\text { CMIN/d } \\
\boldsymbol{f}\end{array}$ & $\boldsymbol{P}$ & GFI & AGFI & CFI & IFI & NFI \\
\hline 1174.106 & 441 & 2.662 & 000 & 0.839 & 0.807 & 0.910 & 0.911 & 0.864 \\
\hline TLI & RMSE & & & & & & & \\
& $\mathbf{A}$ & & & & & & & \\
\hline 0.899 & 0.065 & & & & & & & \\
\hline
\end{tabular}

This study further tested the validity of the constructs. Two types of validity tests were conducted: convergent validity which indicates the agreement among the measures of the same construct on what they are designed to measure. A construct is said to have a good convergent validity when all its indicators share high common proportion of variance. According to Hayes and Scharkow (2013), a convergent validity of a construct can be determined based on the following measures: average variance extracted (AVE), factor loading and construct reliability. AVE is the average amount of variance in the criterion variable that is explained by a predictor variable to which it is theoretically related. AVE of 0.5 and above indicates an adequate convergent validity. Therefore, the constructs of this study have achieved a good convergent validity based on their AVE value as shown in Table 2.

Table 2 Reliability and convergent validity of the measurement mode

\begin{tabular}{ccccc}
\hline Construct & Item & $\begin{array}{c}\text { Standardized } \\
\text { Factor Loading }\end{array}$ & $\begin{array}{c}\text { Composite } \\
\text { Reliability }\end{array}$ & $\begin{array}{c}\text { Average } \\
\text { Variance } \\
\text { Extracted }\end{array}$ \\
\hline Attitude & ATT1 & 0.70 & 0.72 & 0.596 \\
& ATT2 & 0.93 & & \\
& ATT3 & 0.70 & & \\
& ATT4 & 0.69 & & \\
& ATT5 & 0.58 & 0.78 & \\
\hline Subjective norms & SN1 & 0.83 & & \\
& SN2 & 0.81 & & \\
& SN3 & 0.70 & & \\
& SN4 & 0.78 & & \\
& SN5 & 0.81 & & \\
\hline
\end{tabular}


Muhammad Salisu Khalil, Ho Yuek Ming, Latifah Abd Manaf, Amir Hamzah Sharaai, \& Aliyu Baba Nabegu Income Perspective on the Factors Influencing Households' Recycling Intention: Implications from the Extended Theory of Planned Behaviour

\begin{tabular}{|c|c|c|c|c|}
\hline Perceived & PBC1 & 0.73 & 0.76 & 0.568 \\
\hline \multirow[t]{4}{*}{ behavioural control } & $\mathrm{PBC} 2$ & 0.83 & & \\
\hline & PBC3 & 0.74 & & \\
\hline & PBC4 & 0.91 & & \\
\hline & PBC5 & 0.62 & & \\
\hline \multirow[t]{6}{*}{ Personal norms } & PN1 & 0.76 & 0.79 & 0.603 \\
\hline & PN2 & 0.82 & & \\
\hline & PN3 & 0.73 & & \\
\hline & PN4 & 0.90 & & \\
\hline & PN5 & 0.94 & & \\
\hline & PN6 & 0.61 & & \\
\hline \multirow{5}{*}{$\begin{array}{c}\text { Consequences } \\
\text { awareness }\end{array}$} & $\mathrm{AC} 1$ & 0.93 & 0.79 & 0.590 \\
\hline & $\mathrm{AC} 2$ & 0.74 & & \\
\hline & $\mathrm{AC} 3$ & 0.69 & & \\
\hline & $\mathrm{AC} 4$ & 0.92 & & \\
\hline & $\mathrm{AC} 5$ & 0.71 & & \\
\hline \multirow[t]{4}{*}{ Intention to recycle } & INTR1 & 0.83 & 0.80 & 0.535 \\
\hline & INTR2 & 0.79 & & \\
\hline & INTR3 & 0.70 & & \\
\hline & INTR4 & 0.91 & & \\
\hline \multirow{3}{*}{$\begin{array}{l}\text { Perceived lack of } \\
\text { facilitating } \\
\text { conditions }\end{array}$} & PLFC1 & 0.92 & 0.81 & 0.510 \\
\hline & PLFC2 & 0.71 & & \\
\hline & & & & \\
\hline
\end{tabular}

Factor loading is another important method for testing convergent validity. A minimum acceptable value of a standardised factor loading is between 0.5 and 0.7 or even higher as asserted by Hayes and Scharkow (2013). Based on this recommendation, the indicators of all the constructs of this study have a good factor loading as indicated in Table 2. Another measure for testing convergent validity is construct reliability (CR), which refers to a level at which indicators of a construct consistently measure what they are expected to measure (Ary, Jacobs, Irvine, \& Walker, 2013). A CR value of 0.6 to 0.7 or higher is acceptable. A higher CR indicates a high internal consistency between the indicators representing a latent variable (Hayes \& Scharkow, 2013). Based on the above criterion, this study has achieved a reliability test indicating that there is internal consistency among the indicators of the constructs.

Furthermore, a test for discriminant validity (DV) was conducted in this study. The results of discriminant validity (Table 3) for the constructs of this study show that the AVE value of all the constructs is greater than the squared multiple correlations between them. This suggests that the individual constructs are distinct, hence discriminant validity was achieved.

Table 3 Discriminant validity index summary for the construct

\begin{tabular}{llllllll}
\hline Construct & PBC & PN & ATT & SN & INTR & AC & PLFC \\
\hline PBC & $\mathbf{0 . 7 5 3}$ & & & & & & \\
PN & 0.162 & $\mathbf{0 . 7 7 6}$ & & & & & \\
\hline
\end{tabular}


PLANNING MALAYSIA

Journal of the Malaysia Institute of Planners (2019)

\begin{tabular}{llllllll}
\hline ATT & 0.300 & 0.318 & $\mathbf{0 . 7 7 2}$ & & & & \\
SN & 0.295 & 0.015 & 0.169 & $\mathbf{0 . 7 2 4}$ & & & \\
INTR & 0.173 & 0.506 & 0.287 & 0.034 & $\mathbf{0 . 7 3 1}$ & & \\
AC & 0.46 & 0.52 & 0.43 & 0.49 & 0.40 & $\mathbf{0 . 7 6 8}$ & \\
PLFC & 0.44 & 0.40 & 0.17 & 0.14 & 0.38 & 0.14 & $\mathbf{0 . 7 1 4}$ \\
\hline
\end{tabular}

\section{Results of the Structural Equation Modeling (SEM)}

The current study employed the use of SEM to investigate the causal relationships among the variables. Overall, the results show that the independent variables collectively explain 58\% variance in the recycling intention. The result shows that the structural model has a good fit as it achieved the recommended fit indices as follows: $\chi^{2}(\mathrm{CMIN})=1208.706(\mathrm{df}=441)$, relative $\chi^{2}(\mathrm{CMIN} / \mathrm{df})=2.741$, $\mathrm{GFI}=0.835, \mathrm{AGFI}=0.803, \mathrm{CFI}=0.905, \mathrm{IFI}=0.906, \mathrm{NFI}=0.856, \mathrm{TLI}=0.893$, and RMSEA $=0.067$.

The result of the SEM analysis reveals that the paths from attitude to recycling intention and from subjective norms to recycling intention were significant with standardised regression weight $(\beta=0.599, \mathrm{p}<0.001)$ and $(\beta=$ $0.081, p<0.05)$ respectively. The paths from personal norm to recycling intention and from consequences awareness to recycling intention were also significant $(\beta$ $=0.136, p<0.05)$ and $(\beta=0.114, p<0.05)$ respectively. The path from perceived lack of facilitating condition to recycling intention was also significant but negative $(\beta=-0.148, p<0.05)$ indicating that the more people perceived there is lack of recycling facilities and local collection, the lower will be their intention to recycle. However, the path from perceived behavioural control to recycling intention was not significant $(\beta=0.019, \mathrm{p}=0.592)$ as shown in Table 4. Thus, this result shows that $\mathrm{H} 1, \mathrm{H} 2, \mathrm{H} 4, \mathrm{H} 5$ and $\mathrm{H} 6$ were supported, but $\mathrm{H} 3$ was not supported. Attitude has the highest regression weight $(\beta=0.599)$ which made it the strongest predictor of recycling intention, meaning that for every 1 point increase in ATT, RI increases by 0.599 points.

Table 4 Standardised regression weight in the structural equation model

\begin{tabular}{ccccc}
\hline $\begin{array}{c}\text { Hypothesised } \\
\text { Relationship }\end{array}$ & S.E & $\begin{array}{c}\text { Standardised } \\
\text { Regression Weight } \\
\text { Estimate (B) }\end{array}$ & CR & p \\
\hline INT <--- ATT & 0.073 & 0.599 & 8.434 & 0.000 \\
INT <---SN & 0.034 & 0.081 & 2.062 & 0.003 \\
INT <--- PBC & 0.053 & 0.019 & 0.521 & 0.592 \\
INT <---PN & 0.085 & 0.136 & 2.211 & 0.033 \\
INT <--- AC & 0.075 & 0.114 & 1.129 & 0.026 \\
INT <--- PLFC & 0.064 & -0.148 & -2.540 & 0.001 \\
\hline
\end{tabular}

\section{The Moderation Analysis of Households Income Level}

The analysis of the moderating effect was carried out using Multi-Group Analysis. This method as posited by Samah (2016) can be executed by 
Muhammad Salisu Khalil, Ho Yuek Ming, Latifah Abd Manaf, Amir Hamzah Sharaai, \& Aliyu Baba Nabegu Income Perspective on the Factors Influencing Households' Recycling Intention: Implications from the Extended Theory of Planned Behaviour

determining the moderating impact on the overall model as well as on each path in the structural model.

To test the moderating effect on the overall structural model, Unconstrained and Measurement Residual Models were created and compared based on their goodness-of-fit indices. If the unconstrained model has a smaller chi-square and degree of freedom as compared to the measurement residual model, then the unconstrained model is said to be better than the measurement residual model, implying that there is moderating effect on the overall model as suggested by Samah (2016). Based on this method, the results show that there is moderating effect of income on the overall structural model.

To test the moderating effects of households income level on the individual Path, this study used procedure suggested by Hair et al. (2010), which suggests that a relationship path is said to be moderated if: Beta $(\beta)$ for Group 1 is significant, however that of Group 2 is not significant, or Beta $(\beta)$ for both groups (low and high incomes groups) is significant, nonetheless, one is positive and the other is negative.

Therefore, the result of the moderating test reveals that three of the six paths were moderated by income. These include: attitude-recycling intention [low income $(\beta=1.058, \mathrm{p}=0.003)$ and high income $(\beta=-0.155, \mathrm{p}=0.501)]$, personal norms - recycling intention [low income $(\beta=1.007, \mathrm{p}=0.008)$ and high income $(\beta=0.501, p=0.213)]$, and perceived lack of facilitating conditionsrecycling intention [low income $(\beta=0.096, p=0.009)$ and high income $(\beta=$ $0.529, \mathrm{p}=0.000)]$, whereas the other three paths; subjective norms-recycling intention [low income $(\beta=0.022, \mathrm{p}=0.710)$ and high income $(\beta=0.127, \mathrm{p}=$ $0.405)$ ], perceived behavioural control-recycling intention [low income $(\beta=$ $0.032, p=0.313)$ and high income $(\beta=0.168, p=0.231)]$, and awareness of consequences - recycling intention [low income $(\beta=0.250, \mathrm{p}=0.000)$ and high income $(\beta=0.577, \mathrm{p}=0.041)]$ were not moderated by households' income as shown in Table 5. This result shows that $\mathrm{H} 7, \mathrm{H} 10$, and $\mathrm{H} 12$ were supported (but not $\mathrm{H} 8, \mathrm{H} 9$, and $\mathrm{H} 11$ ).

Table 5 Result of moderation effect of income on the relationships between the independent variables and recycling intention

\begin{tabular}{cccc}
\hline Constructs & $\begin{array}{c}\text { Observations in } \\
\text { Each Group }\end{array}$ & $\begin{array}{c}\text { Standardised } \\
\text { Regression Weight } \\
\text { Estimate }(\boldsymbol{\beta})\end{array}$ & $\begin{array}{c}\text { p- } \\
\text { value }\end{array}$ \\
\hline Attitude towards recycling & 201 & 1.058 & 0.003 \\
Low income & 192 & -0.155 & 0.501 \\
High income & & & \\
\hline Subjective norms toward & 201 & 0.022 & 0.710 \\
recycling & 192 & 0.127 & 0.405 \\
Low income & & & \\
High income & & & \\
\hline
\end{tabular}


PLANNING MALAYSIA

Journal of the Malaysia Institute of Planners (2019)

\begin{tabular}{cccc}
\hline $\begin{array}{c}\text { Perceived behavioral } \\
\text { control to recycling } \\
\text { Low income }\end{array}$ & & & \\
High income & 192 & 0.032 & 0.313 \\
\hline $\begin{array}{c}\text { Personal norms toward } \\
\text { recycling }\end{array}$ & & 0.168 & 0.231 \\
$\begin{array}{l}\text { Low income } \\
\text { High income }\end{array}$ & 201 & 1.007 & \\
\hline Awareness of consequences & 192 & 0.501 & 0.008 \\
of recycling & & & 0.213 \\
Low income & 201 & 0.250 & \\
High income & 192 & 0.577 & 0.000 \\
\hline $\begin{array}{c}\text { Perceived lack of } \\
\text { facilitating conditions }\end{array}$ & & & \\
Low income & 201 & 0.096 & 0.009 \\
High income & 192 & -0.529 & 0.000 \\
\hline
\end{tabular}

\section{Discussion and Policy Implication}

The SEM result shows that attitude and subjective norms have a significant and positive influence on recycling intention, which is consistent with the theoretical expectation by Ajzen (1991) and the findings from the past literature such as Khalil et al. (2017), Karim Ghani, Rusli, Biak and Idris (2013), Tonglet, Phillips and Read (2004). However, perceived behavioural control did not significantly predict recycling intention. This finding is congruent with the previous researches by Chen and Tung, (2010), and Wan et al., (2014). Ajzen (1991) also posited that when perceived behavioural control is low, the behavioural intention to perform environmentally friendly behaviour may likely be low. The insignificant effect of $\mathrm{PBC}$ on recycling intention may be because the study area lacks formal recycling system, with lack of recycling facilities and local collection, which can affect households' perceived control on recycling. This is especially in high income areas where households are more concerned about the availability of recycling facilities, which is directly linked to their perceived control over recycling.

The incorporated variables; personal norm, consequences awareness, and perceived lack of facilitating conditions have also significantly influenced recycling intention. Past researches have reported that personal norm has a significant influence on recycling behavioural intention (Wan et al., 2014; Xu et al., 2017). The result of the present study shows that households' personal norm towards recycling can be activated more easily when appropriate intervention strategy is in place. Furthermore, the negative causal relationship between perceived lack of facilitating condition and recycling intention suggests that if households perceived that recycling facilities are not available, they may likely have low recycling intention.

The moderating result suggests that when the income level of a household increases, the causal relationship between attitude-intention and personal normsintention tends to diminish. That is to say, high income households may likely 
Muhammad Salisu Khalil, Ho Yuek Ming, Latifah Abd Manaf, Amir Hamzah Sharaai, \& Aliyu Baba Nabegu Income Perspective on the Factors Influencing Households' Recycling Intention: Implications from the Extended Theory of Planned Behaviour

have low attitude towards recycling especially when recycling facilities and local collections are lacking. On the other hand, the attitude of low income households may likely influence their intention to recycle regardless of the availability of recycling facilities. Similarly, the moderating result shows that the causal relationship between perceived lack of facilitating conditions and recycling intention is positive and significant for low income householders; however, the same relationship shows significant but negative for high income households. This suggests that households in high income group are motivated by the availability of recycling facilities, which is directly linked to their perceived control. On the other hand, households in low income group are more concerned about the financial benefit of recycling rather than the recycling facilities as such their low income status may likely influence their recycling intention. This is consistent with the findings of Fisher, Bashyal and Bachman (2012), and Pakpour et al. (2014), but contrary to that of Meyer and Liebe (2010) who reported that higher income consumers are more likely to perform environmentally friendly behaviour.

\section{Policy Implications of the Study}

The results of this study show that perceived behavioural control did not influence households' recycling intention. To improve households' perceived control, authorities should provide appropriate recycling facilities such as curb side collection, drop-off points that are convenient to the households.

Additionally, the significant influence of awareness of consequences on recycling intention in this study underlines the significance of enlightening people about the positive consequences of recycling and the individual and collective responsibility of performing recycling for the benefit of oneself and the community at large.

The findings also suggest that the policy approach should be area specific. For example, the low income households can be encouraged to participate further in recycling by giving them incentives as they tend to be more motivated toward the financial benefits of recycling, whereas, the high income households can be encouraged by providing recycling facilities and local collections in a more convenient and accessible location that would ease their participation.

\section{CONCLUSION}

This study attempted to investigate the moderating effect of income on households' recycling intention. The results indicated that income moderated the positive relationships between attitude - recycling intention, personal norms recycling intention, as well as those between perceived lack of facilitating conditions - recycling intention. While previous researchers have found that recycling intention increases with the increase in income level, the results from 
this study revealed a unique finding that recycling intention decreases with increase in household income. This finding is considered unique as no previous study investigated the moderating effect of income on households' recycling intention. The extended TPB model used in this research will help policy makers to better understand the factors affecting recycling intention.

\section{ACKNOWLEDGEMENTS}

The publication of this article was sponsored by the Universiti Putra Malaysia.

\section{REFERENCES}

Ajzen, I. (1991). The theory of planned behavior. Organizational Behavior and Human Decision Processes, 50(2), 179-211.

Ary, D., Jacobs, L. C., Irvine, C. K., \& Walker, D. (2013). Introduction to Research in Education. Boston, MA: Cengage Learning.

Chen, M.-F., \& Tung, P.-J. (2010). The moderating effect of perceived lack of facilities on consumers' recycling intentions. Environment and Behavior, 42(6), 824-844.

Fisher, C., Bashyal, S., \& Bachman, B. (2012). Demographic impacts on environmentally friendly purchase behaviors. Journal of Targeting, Measurement and Analysis for Marketing, 20(3-4), 172-184.

Hair, J. F., Black, W. C., Babin, B. J., \& Anderson, R.E. (2010). Multivariate data analysis. New York: Pearson Higher Ed.

Hayes, A. F., \& Scharkow, M. (2013). The relative trustworthiness of inferential tests of the indirect effect in statistical mediation analysis: Does method really matter? Psychological Science, 24(10), 1918-1927.

Karim Ghani, W. A., Rusli, I. F., Biak, D. R. A., \& Idris, A. (2013). An application of the theory of planned behaviour to study the influencing factors of participation in source separation of food waste. Waste Management, 33(5), 1276-1281.

Khalil, M., Abdullah, S., Abd Manaf, L., Sharaai, A., \& Nabegu, A. (2017). Examining the moderating role of perceived lack of facilitating conditions on household recycling intention in Kano, Nigeria. Recycling, 2(4), 18.

Krejcie, R. V., \& Morgan, D. W. (1970). Determining sample size for research activities. Education Psychology, 30, 607-610.

Meyer, R., \& Liebe, U. (2010). Are the affluent prepared to pay for the planet ? Explaining willingness to pay for public and quasi-private environmental goods in Switzerland. Population and Environment, 32(1), 42-65.

Pakpour, A. H., Zeidi, I. M., Emamjomeh, M. M., Asefzadeh, S., \& Pearson, H. (2014) Household waste behaviours among a community sample in Iran: An application of the theory of planned behaviour. Waste Management, 34, 980-986.

Pérez-López, G., Prior, D., Zafra-Gómez, J. L., \& Plata-Díaz, A. M. (2016). Cost efficiency in municipal solid waste service delivery: Alternative management forms in relation to local population size. European Journal of Operational Research, 255(2), 583-592.

Suleyman, N., \& Khalil, M. S. (2014). Student perceptions of geography as a discipline: A comparative study: Case studies from Turkey and Nigeria. Germany, Saarland: LAP Lambert Academic Publishing. 
Muhammad Salisu Khalil, Ho Yuek Ming, Latifah Abd Manaf, Amir Hamzah Sharaai, \& Aliyu Baba Nabegu Income Perspective on the Factors Influencing Households' Recycling Intention: Implications from the

Extended Theory of Planned Behaviour

Samah, B. A. (2016). Enhancing extension education research using structural equation modelling. Serdang: Universiti Putra Malaysia Press.

Singh, A. S., \& Masuku, M. B. (2014). Sampling techniques \& determination of sample size in applied statistics research: An overview. International Journal of Economics, Commerce and Management, 2(11), 1-22.

Tonglet, M., Phillips, P. S., \& Read, A. D. (2004). Using the theory of planned behaviour to investigate the determinants of recycling behaviour: A case study from Brixworth, UK. Resources, Conservation and Recycling, 41, 191-214.

Wan, C., Shen, G. Q., \& Yu, A. (2014). The role of perceived effectiveness of policy measures in predicting recycling behaviour in Hong Kong. Resources, Conservation and Recycling, 83, 141-151.

Xu, L., Ling, M., Lu, Y., \& Shen, M. (2017). Understanding household waste separation behaviour: Testing the roles of moral, past experience, and perceived policy effectiveness within the theory of planned behaviour. Sustainability, 9(4), 2-27

Received: $12^{\text {th }}$ January 2019. Accepted: $2^{\text {nd }}$ August 2019 